\title{
MODERN TECHNIQUES IN THE TEACHING OF FRENCH AS SECOND LANGUAGE IN THE INDIAN CONTEXT
}

\section{BRATISH SARKAR}

Assistant Professor, Amity School of Languages, Amity University, Lucknow

Secretary North India-IATF (Indian Association of Teachers of French)

\section{ABSTRACT}

Summary

India has two official languages, Hindi and English, and 18 national languages. French is taught as a fourth language, but as a second foreign language. However, it remains the second foreign language studied in India. It is taught at all levels. As the Elementary / Beginner User: Level-AI, A2, The Independent User: Level-B1, B2 and The Experienced / Advanced User: Level C1, C2. To improve the teaching of the French language to the present day we can use the new applications (a) Enjoy the technology: - You can use iTunes, YouTube, new technologies like Prezi, blubber, Zaption, Blogger, etc.) Blend Student Learning: You can use Music Videos, French TV, FluentU, Podcasts etc. (C) Return your class (FLIP your class): The four pillars of FLIP

- F-Flexible Environment

- L-The Learning Culture

- I-Intentional Content

- P-Professional Experts.

In addition, we can use other resources like La Civilization, French; French Together, Camtasia, Ma France, YouTube, Power Point, etc. (D) Try Gamification: Everyone loves to play games. So, what better way to motivate your pupils than to get them to play games while learning digital dialects, Webquest, the French Games, Ciel Brittany and so on. From January 2017, the CIEP will also offer a full range of open distance training (ODL) directly accessible from its website. It is possible to help develop strong and lasting relations between international and French universities, and to establish a Franco-international academic cooperation network within the framework of the construction of the European knowledge area.

KEYWORDS: French, Digital Technology, Flip Classes, French Games, French Civilization \& Training

Received: Mar 31, 2017; Accepted: Apr 27, 2017; Published: May 23, 2017; Paper Id.: IJELJUN20175

\section{INTRODUCTION}

Communication and language are the main source of human experience. Due to the ever-expanding world market, increased travel opportunities and implications in the Internet world, the importance of foreign languages is higher than before. Therefore, we focus on preparing students who are culturally and linguistically equipped for successful communication in the company's society and abroad. As our country grows and business opportunities are expanding more and more with many multinational companies expanding their business in India, the number of careers that emphasize the importance of learning a second language is enormous. India has two official languages, 
Hindi and English, and 18 national languages. French is taught as a fourth language, but as a second foreign language. Until 1989, French had the status of a second compulsory foreign language in Indian schools. It has become an optional language everywhere, except in the hotel and tourism institutes, where it has remained compulsory. French has lost this status for the benefit of mother tongues. However, it remains the second foreign language studied in India. It is taught at all levels.

\section{The Elementary Beginner User}

Level A1: A level that can understand and use familiar, everyday expressions and very simple statements that meet specific needs. Can introduce or introduce someone and ask a person questions about her - for example, where she lives, what her relationships are, what she belongs to, and so on. And, can answer the same type of questions, and communicate in a simple way, if the interlocutor speaks slowly and distinctly and cooperatively.

Level A2: A level that may include isolated phrases and frequently used phrases related to the immediate areas of priority (e.g., simple personal and family information, shopping, close environment, work). Can communicate in simple away, requiring only a simple and direct exchange of information on familiar and usual subjects. Can describe with simple means its formation, its immediate environment and evoke subjects that correspond to immediate needs.

\section{The Independent User}

Level B1: A level that can include the essential points when a clear and standard language is used and whether it is familiar in work, school, leisure, etc. Can cope in most situations encountered while traveling in an area where the target language is spoken. Can produce simple and coherent speech on familiar topics and areas of interest. Can tell an event, experience or a dream, describe a hope or purpose and briefly explain reasons or explanations for a project or idea.

Level B2: This level may include the essential content of concrete or abstract subjects in a complex text, including a technical discussion in its specialty. Can communicate with a degree of spontaneity and ease such as a conversation with a native speaker with no tension for either one. Can express itself in a clear and detailed manner on a wide range of subjects, give an opinion on a current topic and explain the advantages and disadvantages of different possibilities.

\section{Experienced Advanced User}

Level C1: Level which can include a wide range of long and demanding texts, as well as enter implicit meanings. Can express himself spontaneously and fluently without seemingly having to search for his words. Can use language effectively and flexibly in social, professional or academic life. Can express itself on complex subjects in a clear and well structured way and demonstrate its control of the tools of organization, articulation and cohesion of discourse.

Level C2: Level that can effortlessly include everything that he / she read or hear. Can summarize facts and arguments from various written and oral sources, consistently. Can express itself spontaneously, very fluently and precisely and can make distinct nuances of meaning in relation to complex subjects.

To improve the teaching of the French language to the present day we can use the new applications (A) Enjoy the technology: -

* iTunes offers free 24/7 radio stations and podcasts in French (some for beginners!) And most cable distribution packages include at least one point programming in French. * There are many mobile applications that can help you memorize words, the most popular being the Ling Ling application based on spaced repetition. You can devote 20 minutes 
Modern Techniques in the Teaching of French as

a day to memorize 750 words per month.

*YouTube has dozens and dozens of resources in French for beginners. * Go to your local video library or search the net, sometimes you will find other lesser known movies (or documentaries) available for free.

* Watch your favorite movies in English voice-over or subtitled in French. Even if you do not know French at all, the choice of a film that is familiar to you will help you to establish the context of the language

* Listen to the French program in action on your local public broadcasting station* Make French the first thing you see on your computer. Put a website in French as a homepage* You can find speakers whose French is the mother tongue on many websites, such as students of the world. It will be easier to make friends and improve your knowledge of French. Ask them to help you improve your knowledge and offer to teach them English in return.

This is the era of technology, and more and more applications are being invented to help teachers. So, why not make use of these resources? Most of them offer a free plan that can be updated if you need to use more advanced features.

\section{Prezi}

Take your slides to the next level. Prezi is a cloud application presentation. The designers claim that "Unlike slides, Prezi is a canvas zoom with unlimited possibilities. "Prezi is a non-linear tool and allows you to work on a blank page.

Just like PowerPoint, Prezi allows you to insert images, text, sounds, animations and videos. So if you want to give a new type of presentation, it is the one to try.

\section{Blubbr}

Creating trivia. Blubbr video games are a fun way to create quizzes and trivia questions. It allows you to select a YouTube video and add questions to it. It has several categories to choose from, or you can upload your own video. It is fun and interactive for learners. A tip, however, not to choose a video that is more than 15 minutes.

\section{Zaption}

Venture on a video tour. Zaption is another interesting tool that can be used to create video lessons for your students. You can choose to use the videos in their gallery, or you can upload your own video. With Zaption visits, you can generate interest in a topic before you introduce it, or questions can give rise to a discussion in class.

\section{Blogger}

Ask students to make blogs teaching. Blogs are a great way to get your students to collaborate and create something related to the topic you are teaching. Let them check out some of the blogs that teach French. Next, ask your students to create their own version of a blog teaching on Blogger. In this way, they must come to grips with the object-be it grammar, literature or culture in order to teach others.

\section{Student Blend Learning}

Blended learning is one of the new teaching strategies of the modern classroom. It is a hybrid method that has students learning both online and in a place of brick and mortar. Usually, teachers give face-to-face lessons, and then use a platform such as Moodle as a backup. But, there are also other cool resources you can use, such as the following: 


\section{Music Videos}

A good method to use in the classroom of mixed learning is the use of songs to stimulate enthusiasm. And, what better way to use music videos? There are a lot of music videos on YouTube. You can even hear "La Marseillaise" with French and English subtitles. It is a fun way to teach them culture and vocabulary, not to mention understanding. Another advantage is that the songs teach them the rhythm and intonation of the tongue.

Discover exciting and easy songs on YouTube, featuring songs for beginners. Or if you prefer something more advanced, what some of the classics like Edith Piaf "Life in pink" or Jacques Brel "Do not leave me" I like the use of Celine Dion "For the remainder of That you "to strengthen the use of the future.

Crazy French has an extensive collection of songs with English translations, while TV5 has a variety of music videos with spreadsheets and transcriptions for three language levels: A2 (Elementary), B1 (Intermediate) and B2 (Advanced).

\section{French Television}

French television is another fabulous way to attract your students' attention and increase motivation. The best channel I found (which is accessible in the US) is TV5, which has its own section on French language divided into Learn French and French Teach. It also has a section entitled Discovering French which includes a dictionary, plus a section titled French Parlons which has short video clips or video clips about France and its culture.

The teacher's section has an excellent resource called September days on the planet. It consists of a news report with French subtitles that spans seven days. The levels include A2, B1 and B2, and each clip is accompanied by a French transcript (which can be used as a translation exercise), a teacher's card (PDF or DOC) and a learner card. French songs to pronunciation and vocabulary lessons, TV5 has it all!

\section{FluentU}

As a smooth immersive learning platform that completely eliminates the hours you would otherwise want to spend looking videos on YouTube, FluentU is a very useful application in the modern classroom. FluentU takes real-world videos resembling music videos, inspiring lectures, news, cartoons and film trailers and transforms them into personalized learning. With six levels, from beginner to native, and categories covering the arts and entertainment to society and politics, there is something that will interest all students.

Each word comes with a definition in context, imagery, audio and multiple examples of sentences. You can even click on a word to see how it is used in other videos on FluentU's unique "learning mode" site then takes these authentic videos and transforms them into French learning. The lessons are fully customized, so the student's learning history is taken into account when presenting the questions. The FluentU algorithm defines students for the success of teaching them based on what they know.

Not only can you develop lessons around FluentU and recommend it for individual practice at home, but with the assignment function handy, you can also assign specific videos to each of your classes. Easily display each student and progress, no class ranking required! 


\section{Podcasts}

Podcasts are readily available and offer a variety of topics. They are useful for pronunciation and vocabulary purposes, as well as being an exercise in understanding. Try to use learning with French-Podcasts.com, which has various categories. You can listen to the podcast (Sometimes with simultaneous translation in English), then download the PDF transcript. This will help your learners improve their oral comprehension, pronunciation and vocabulary.

My French has short, simple podcasts that are ideal for beginners. From simple greetings and grammar to French culture, this site is a good accompaniment for all courses. These conversations in French are another impressive site, which has a series of MP3 files your learners can listen to. You must click on the "dialogs" button to take a series of conversations. After the dialogue is transcription, then two other podcasts that question the learner (in French) on the content. As you can tell, a blended learning program is more flexible and easier to customize, giving you a rich environment from which to work.

\section{Return Your Class (FLIP Your Class)}

A returned classroom reverses traditional teaching methods: Learners get the subject and the material recorded online at home, while class time is devoted to doing exercises and discussing the subject. This will allow you as a teacher to devote more time to problem areas. A returned class on French culture would be ideal, and here are some resources to help you do that.

\section{Goals}

To allow students to better control when, where, and how to engage in the learning process by moving from the group learning space to the individual learning space, and the resulting group space is Transformed into a dynamic and interactive learning environment where faculty student guides as they apply concepts and engage creatively in the subject to achieve higher levels of cognitive learning

\section{The Benefits of Flipped Class}

- The participation of the active student

- High level of student interaction with peers and course teachers

- The student is not only to gain a better understanding of the content, but also gain insight into how to use it.

- Devoting class time to the application of concepts gives instructors a better opportunity to identify gaps in student understanding.

- More responsibility for learning rests on the shoulders of students while giving them a greater impulse to experiment.

- Using technology to give students control over their interactions has a positive effect on student learning.

- Allows students to pause and rewind their teacher

\section{The Four Pillars of F-L-I-P}

- F - Flexible environment Flipped Learning allows a variety of learning modes; Faculty can physically reorganize learning spaces to accommodate a lesson or unit, to take charge of group work or an independent study. They 
create flexible spaces in which students choose when and where to learn.

- $\quad$ L-The Learning Culture

- Flipped learning model deliberately moves instruction to a learner-centered approach, where in time class is devoted to exploring topics more in depth and creating rich learning opportunities.

- I - Intentional Content

- $\quad$ Flipped Learning Faculty continually thinks about how they can use the Flipped learning model to help students develop conceptual understanding, as well as mastery of the procedure. They determine what they should teach and what students should explore the materials themselves.

- P- Professional Experts

- Pedagogy requires a faculty of being a professional expert, who can continuously observe their students, providing them with relevant feedback at the moment, and evaluating their work. There are also other sites such as French civilization, French together, Camtasia, Ma France, YouTube, PowerPoint by which your students can enrich their communication skills.

\section{Try Gamification}

Everyone loves to play games. So what better way to motivate your students than to get them to play games while learning?

\section{Digital Dialects}

If you are looking for easy online games that can enhance vocabulary, then Digital Dialects have a variety of themes from which to choose. Your students can hear the pronunciation, learn the word, and then play a game.

\section{Web quest}

Another way to play is to send learners on a webquest so they can discover the French culture and customs. A good site to find a webquest on France is TES. You must subscribe for access, but it is free.

\section{The French Games}

The French Games have basic games with over 100 subjects. Learners first choose a topic, then learn the topic using the site and free tutorials, and finally play a game.

\section{CielBrittany}

Ciel Bretagne offers a variety of games on grammar and vocabulary points. Clicking on each game name will open a PDF file containing all the rules, instructions and documents-that you need to save or print. Are you ready to join the modern classroom using these strategies? If you were not before, you are now! Choose a solid strategy to try and energize your courses today! Good opportunity and good job!

Today, many young Indians want to study in France and in French-speaking countries. The French concept "education" and the English concept "education" are not equivalent. In good linguistics, the term "education" should be translated by the French term "instruction." But in order to avoid ambiguity, the term "education" will be translated as 
Modern Techniques in the Teaching of French as

"education" in the following text. Moreover, the term "school education" will be used in a more restrictive sense.

- Education programs should take into account the obvious differences in the traditions of young Indians, as well as the often less obvious differences in their scale of values and motives.

- The Provincial Ministries of Education, in collaboration with the Education Division of the Indian Affairs Branch, should encourage universities to provide, as part of teacher training, language studies involving the study of Comparative grammar.

- The Indian Foreign ministry, through its Programs Division and under arrangements with outside specialists, should develop instructional materials on Indian languages that would be used by course holders.

- The Indian Foreign ministry Branch conducts supplementary training programs by organizing summer courses, evening classes and on-site training courses. Thus, teachers and other staff could acquire a methodical knowledge of the people with whom they work. We also recommend that school boards and federations, as well as provincial ministries of education, encourage teachers to take these courses and facilitate them. The Indian Affairs Branch is increasingly engaged in finding employment for Indian youth who have settled in the city.

\section{Training Program}

The International Center for Educational Studies (CIEP) offers you a range of continuing education programs, guided by the missions it carries out in the fields of education and training, the French language, French-language certifications, Recognition of diplomas and international mobility. These trainings are designed and carried out by specialists in the questions you are dealing with today to prepare your future project, whether professional or personal. From January 2017 onwards, the CIEP will also offer a full range of open distance training (ODL) directly accessible from its website.

\section{Academic Exchanges}

\section{Goals}

To support the development of strong and lasting relations between international and French universities and to establish a Franco-international university cooperation network in the framework of the construction of the European knowledge area. In the school system, the success or failure of a student depends on his or her abilities, the competence of the teachers and the ability of the individual to communicate with others in different ways.

\section{REFERENCES}

1. Asher, J, Learning Another Language through actions: The complete Teacher's Guide book,Los Gatos, CA:Sky Oaks Productions, 1977.

2. Brown,H.D, Teaching by Principles: An Interactive Approach to Language Pedagogy,Englewood Cliffs: Prentice Hall Regents, 1994.

3. Carter, R and Mc Cathy,M (eds.), Vocabulary and language Teaching, London:Longman,1988.

4. Cerezal,F, "Foreign language teaching methods" in McLaren,N and Madrid,D(eds.): A Handbook for TEFL, Alcoy: Marfil,1996.

5. Chafe,A, "Cooperative Learning and the second language classroom" 
6. [Internet document available at http://www.cdli,ca/ achafe/cooplang.html]

7. Gattegno, C,Teaching Foreign Languages in School : The Silent Way, New York : Educational Solutions, Inc, 1972.

8. [Internet document available at http://www.ambafrance-in.org/French-Education-Office]

9. [Internet document available at http://www.fluentu.com/education-language-schools/] 